\title{
El robo del siglo a plena luz del día
}

\author{
James M. Cypher"
}

\begin{abstract}
La llamada reforma energética aprobada a finales de 2013 propinó la puntilla
a Petróleos Mexicanos. Con ello el gobierno cierra un ciclo donde la generación
\end{abstract} y distribución de energía estaba controlada por el Estado. No desaparecerán las empresas petrolera y eléctrica, pero dejarán de ser las mayores empresas públicas de México.

Ante los signos de agonía constitucional, el gobierno desplegó una campaña mediática que aseguraba que "el petróleo seguirá siendo de los mexicanos". Sin embargo, las grandes compañias privadas internacionales, luego de siete décadas y media, ahora pueden proclamar una frase semejante, pero a su favor.

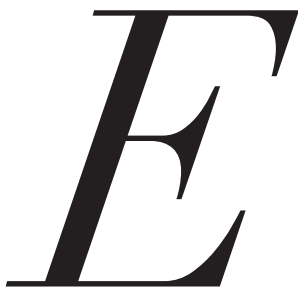

L 2I DE DICIEMBRE DE 2013 entró en vigor el decreto oficial del presidente de México, Enrique Peña Nieto, que termina con 75 años de historia de Petróleos Mexicanos (Pemex). El decreto significa también el cierre de la era en que el sistema de generación y distribución de energía eléctrica - bajo las figuras de la Compañía de Luz y Fuerza del Centro (ClyFC) (I96o2009) y la Comisión Federal de Electricidad (CFE) (I9372013) - había estado controlado por el Estado. En sentido estricto, ni Pemex ni CFE dejarán de existir, pero

*Profesor-investigador del Doctorado en Estudios del Desarrollo de la Universidad Autónoma de Zacatecas, México.

Traducción de Cynthia Arredondo Cabrera.

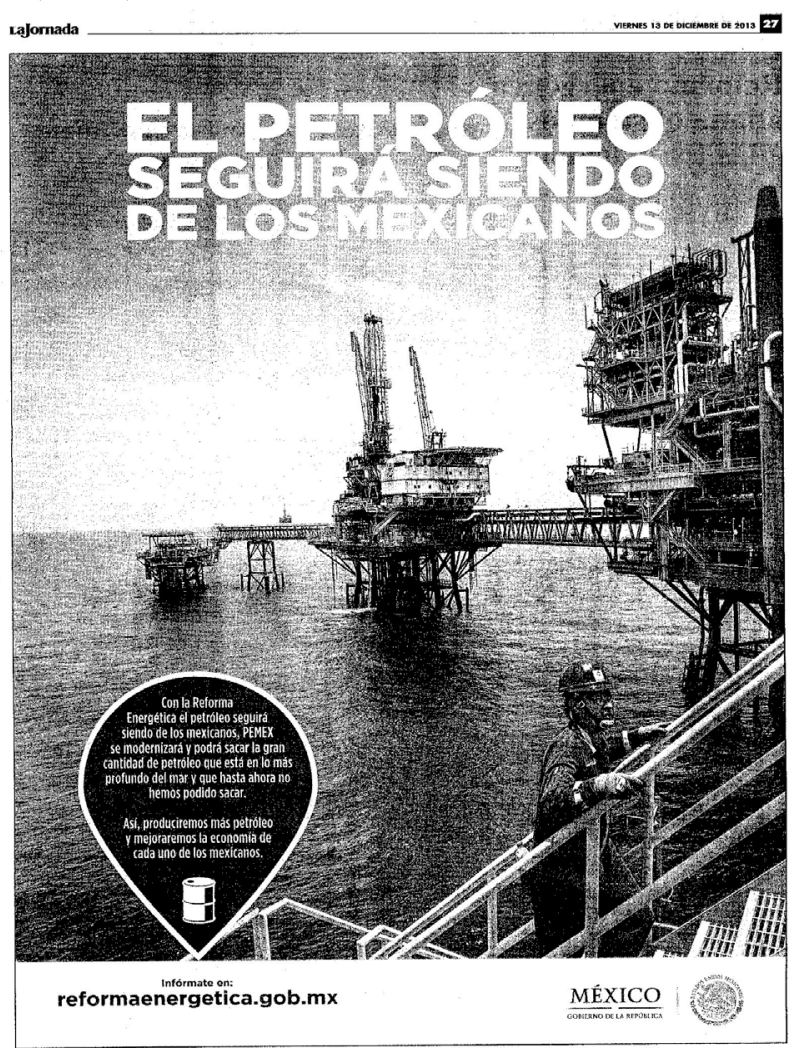


rápidamente se convertirán en sombras de lo que fueron: las dos mayores empresas públicas de México. En respuesta a estos grandes cambios, el intelectual Arnaldo Córdova reconoció que "la Constitución está moribunda", mientras que Cuauhtémoc Cárdenas declaró: "Nunca, a lo largo de nuestra historia independiente, el país había visto tan desmanteladas las defensas de su soberanía y autodeterminación". Por su parte, el gobierno mexicano saturó los medios de comunicación con notas en primera plana, en la más prominente de las cuales se podía leer: "El petróleo seguirá siendo de los mexicanos".

Las reformas a las leyes secundarias en materia energética, que tendrán lugar durante 2014, y la manera en que entrarán en vigor, revisten un alto nivel de complejidad. Ahora, en lugar de trabajar con Pemex al amparo de contratos de prestación de servicios con comisiones fijas, las corporaciones privadas podrán acceder a acuerdos que contemplan el reparto de utilidades por la producción de petróleo y gas. Estas corporaciones podrán obtener las licencias y contratos necesarios para operar sus propias plataformas petrolíferas. Técnicamente, mientras los yacimientos de petróleo se encuentren en el subsuelo, el Estado mexicano seguirá siendo el único propietario de los hidrocarburos. En la boca del pozo, la propiedad del petróleo cambiará de titular al ser transferida al "propietario privado"; también podrán ser inscritas con antelación en los registros de contabilidad de la empresa privada las "reservas probadas de petróleo" que aún se encuentran bajo tierra. Hacer estas "reservaciones" de petróleo mexicano en los estados contables anuales es de suma importancia para las gigantes petroleras transnacionales, que hoy se preparan para operar en México, pues las "reservas probadas de petróleo" constituyen la base principal para la valoración de estas empresas y la determinación de los precios de sus acciones bursátiles.

Los críticos mexicanos han expresado sin cesar que los profundos cambios políticos de diciembre son "entreguistas": la soberanía nacional es entregada a los intereses extranjeros. Asimismo, evocan el imaginario de la época del porfiriato (I876-г9го), cuando el presidente de Estados Unidos, Ulysses S. Grant (I869-1877), se refirió a México como una "mina magnificente" a disposición de Estados Unidos. Este enfoque endémico habitualmente resta importancia a las formas en que los grandes grupos oligárquicos mexicanos trabajan los apalancamientos en el proceso de formulación de las políticas nacionales a favor de sus intereses. Las empresas mineras, incluyendo las grandes corporaciones mexicanas como Grupo México, Industrias Peñoles y Frisco, actualmente controlan cerca de $25 \%$ del territorio de México bajo concesiones lucrativas exentas de impuestos y operan concesiones que fueron obtenidas mediante el pago de entre $\$ 5$ y $\$$ io6 pesos por hectárea. De manera discrecional se ha incluido en la nueva legislación la autorización para que las gigantes mineras (hasta $60 \%$ mexicanas) puedan hacer perforaciones en estos vastos territorios en busca de petróleo y gas. ${ }^{2}$ El primero en saltar para aprovechar esta oportunidad fue Grupo México, la corporación minera más grande del país, que anunció sus planes de hacer las perforaciones de gas de lutita dentro de sus concesiones durante 20I/. ${ }^{3}$
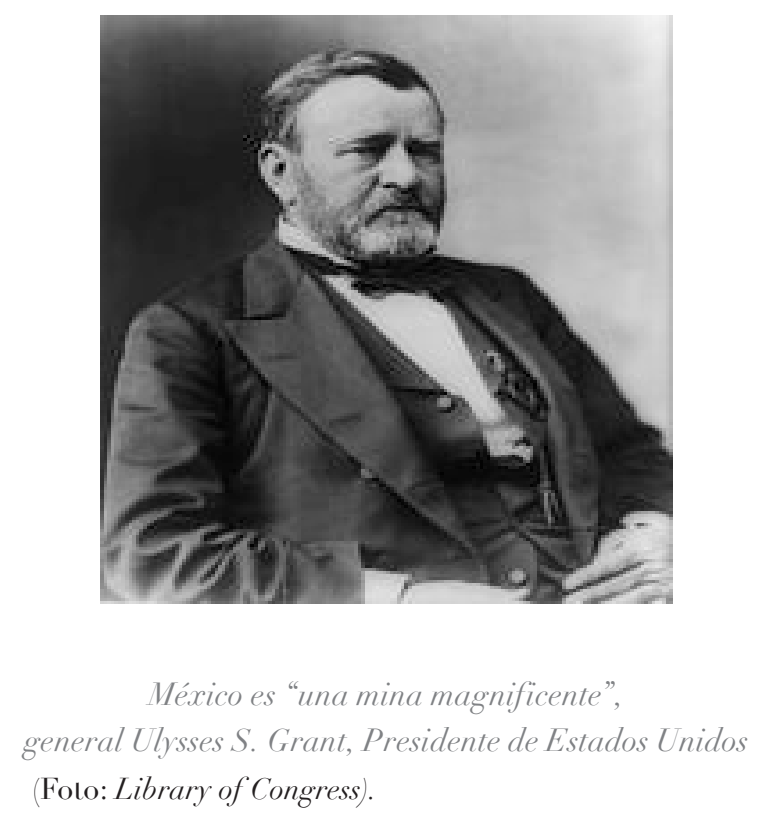

La INDUSTRIA DE LA ENERGía ELÉCTRICA

La creación de la CFE como empresa pública fue parte de un programa más amplio para fortalecer el sector agrario a través de la provisión de energía eléctrica a zonas rurales a comienzos de I937 bajo la administración del presidente Lázaro Cárdenas. Más tarde, en I96o, el presidente Adolfo López Mateos nacionalizó la industria eléctrica, resolviendo una vieja disputa acerca de la gestión y reinversión de las empresas extranjeras de energía eléctrica, que entonces controlaban alrededor de 70\% del mercado. La adquisición pública dio lugar a la creación de la Clyfc. Sin embargo, en 2009 el presidente Felipe Calderón decretó la "liquidación" de la CLyFC, y el despido de sus 44,ooo trabaja- 
dores. La "reestructuración" de la industria eléctrica ejecutada por Calderón, si bien fue considerada una acción audaz, resultó precursora de lo que vendría después.

Ahora la CFE operará como una entidad meramente administrativa, y será propietaria de los sistemas de transmisión y distribución, mientras que las empresas privadas podrán poseer y controlar las actividades de generación de energía dirigidas, sobre todo, a usuarios industriales. Actualmente, se pronostica que la finalización de esta transferencia del sector público al privado terminará en 20I8, cuando existirán 27 nuevas plantas termoeléctricas y ı, oоo km de nuevos gasoductos. Las empresas privadas serán propietarias mayoritarias. En conjunto, las inversiones privadas y públicas en la nueva industria de energía eléctrica están programadas para alcanzar un impresionante total de $\$ 63$ mil millones de dólares, ${ }^{4}$ de los cuales $\$ 50$ mil millones se destinarán a la revitalización de la red de gasoductos. Estos gastos se cubrirán primordialmente con fondos provenientes del gobierno.

\section{LA COMPLEJIDAD DE LOS CAMBIOS LEGALES}

Hasta diciembre de 20I3, como entidades estatales Pemex y CFE disfrutaron del más alto estatus posible. En sus orígenes fueron declaradas entidades de carácter "social" y sus servicios calificados como "ofrecidos tradicionalmente por el Estado", por lo que se denominaron entidades "estratégicas". En tanto monopolio natural, Pemex produjo ganancias extraordinarias que los vendedores obtuvieron a través de la valorización de los recursos naturales no renovables. Por ser sector "estratégico", estos beneficios eran colectivizados a través del Estado mexicano. La condición colectiva de este recurso tuvo su origen en el artículo 27 de la Constitución de igI7, aplicable también a todos los recursos hídricos y del subsuelo, los cuales son, en última instancia, propiedad de la nación.

Ahora Pemex y CFE han sido declaradas como "empresas productivas del Estado", otorgándoles el mismo estatus que cualquier entidad privada, nacional o extranjera. En tal circunstancia, los sindicatos de trabajadores de estas dos grandes entidades deben renunciar a su estatus especial - incluyendo la participación en numerosas decisiones como miembros del Consejo de Administración - para asumir la condición de "sindicatos industriales" convencionales. Los salarios y prestaciones serán determinados a través de negociaciones cuyas formas aún no han sido definidas. Los obreros tendrán que comenzar de nuevo enfrentando a las dos antiguas empresas paraestatales, todas las demás entidades privadas, público-privadas y subcontratistas, nacionales y transnacionales, que probablemente sean formadas a partir de la nueva legislación. ${ }^{5}$

Para los cerca de 98,ooo empleados de la CFE y los ı5̆, ooo de Pemex (alrededor de $67 \%$ son miembros del sindicato) la posibilidad de despido es todavía incierta, sin embargo resulta ampliamente predecible. El senador Luis Sánchez Jiménez estimó que 40\% del personal actual de Pemex se quedará sin empleo. ${ }^{6}$ Si este cálculo es razonable, serían despidos ı5o,ooo trabajadores, tomando en cuenta el efecto "multiplicador" del empleo. Es decir, contando los efectos directos e indirectos - dado que los petroleros son relativamente bien pagados - , la privatización impactará un estimado de r.5 puestos adicionales de trabajo por cada empleado de Pemex.

Dado el hecho de que una nueva ley laboral nacional se aprobó a finales de 2012 (para aumentar la "flexibilidad" de los acuerdos contractuales y bajar las prestaciones de los nuevos contratados), es prácticamente seguro que las empresas privadas nacionales y extranjeras que entrarán al sector energético no pagarán los salarios al mismo nivel que antes. Aquellos, comparativamente generosos salarios y prestaciones pagados por Pemex y CFE, incluyendo programas de retiro con pensiones de hasta Ioo\% del último monto salarial, pronto se convertirán en un recuerdo digno de la nostalgia de los trabajadores. En la actualidad, los costos laborales representan $64 \%$ de los gastos anuales de Pemex - después de los desmesurados impuestos pagados al Estado - , mientras que las refinerías petroleras en Estados Unidos destinan sólo ıo\% al pago de mano de obra. En general, la participación de los salarios en el producto interno bruto (PIB) de México representa un patético $27 \%$.

PEMEX: AYER Y MAÑANA

En la economía mexicana, Pemex destaca como la empresa más grande. En 20I2, sus ventas anuales equivalieron a las ventas combinadas de las empresas mexicanas ubicadas entre el segundo y quinto lugar por su tamaño (incluyendo CFE, en cuarto sitio). Para 2013, Pemex produjo 3.6 millones de barriles de petróleo por día (o su 
equivalente en gas), lo que la sitúa como la octava empresa más grande de petróleo en el mundo (en contraste al quinto lugar que ocupó en 2003, cuando la producción se situó en 4.2 millones de barriles diarios). Asimismo, en 2012 las ventas fueron de $\$ 1 / 48.7$ mil millones de dólares; de estos ingresos 55\% se pagaron en impuestos al Gobierno Federal, dejando poco para nuevas exploraciones, la depreciación de la planta de producción y el desarrollo de tecnología de vanguardia. ${ }^{8}$ Según Forbes, en 2012 los activos de Pemex fueron valorados en \$4ı 6 billones dólares (sí, billones), cifra 25\% mayor que la de ExxonMobil, considerado el cuarto productor mundial en ese año. ${ }^{9}$ De acuerdo con varias fuentes para 2012, de los tres mayores productores de petróleo en América Latina (entonces todos de propiedad estatal), Pemex era la menos eficiente. Si se toma como punto de comparación "el número de barriles de petróleo por día (y su equivalente en gas) por empleado", el rendimiento de México fue de unos 24 barriles; el de PDVSA de Venezuela, de 25 barriles; y el de la brasileña Petrobras, de 3i barriles. Por su alto grado de eficiencia, vale la pena señalar que el proyecto de desarrollo nacional de Brasil está centrado en Petrobras. ${ }^{\circ}$ Dentro de los círculos industriales, la otrora apreciada PDVSA, a pesar de ser ahora considerado como totalmente ineficaz, supera ligeramente a Pemex."

Pemex: Perspectiva histórica

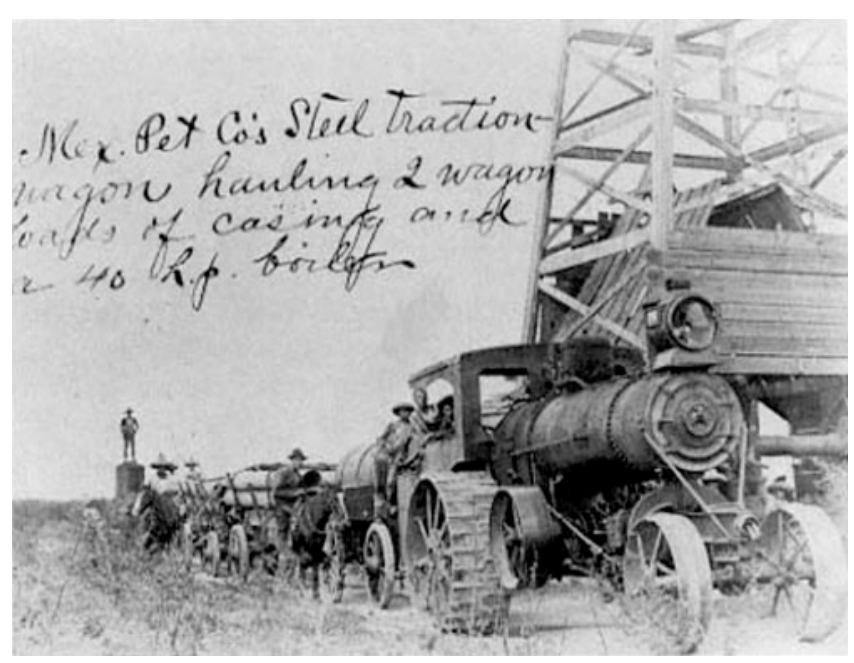

1902: Arrastrando revestimiento para pozos y una caldera en San Luis Potosi para la Mexican Petroleum Company of California, propiedad de Edward Doheny y C.A. Canfield (con torre de perforación hecho de madera al fondo).
Pemex fue fundada en ig34 por el presidente Abelardo Rodríguez con el objetivo de formar una industria petrolera "genuinamente nacional", en un contexto en el que dicha industria estaba bajo el control y propiedad de compañías petroleras extranjeras. Las difíciles condiciones de trabajo provocaron movimientos de huelga en I, 892 ocasiones, entre ig35 y i937. ${ }^{12}$ Después de una prolongada disputa, el presidente Lázaro Cárdenas nacionaliza la industria, una acción muy recordada entre los altos círculos de las grandes petroleras de Texas. ${ }^{3}$ Sin embargo, no fue sino hasta ig5̃2 cuando Pemex llegó a tener una base productiva consolidada. Hasta aquel entonces se habían acrecentado los rumores acerca de la "necesidad" eventual del regreso de las consternadas petroleras internacionales, por supuesto, para beneficio de México. ${ }^{14}$ Parece que ahora la combinación ideológica del centrista partido de Enrique Peña Nieto, el PrI, y sus aliados del partido de derecha, el Partido Acción Nacional (PAN), que ejerció el poder entre 2000 y 2012, la industria petrolera internacional pareciera confirmar estos antiguos rumores, aunque parezca un poco prematuro afirmarlo.

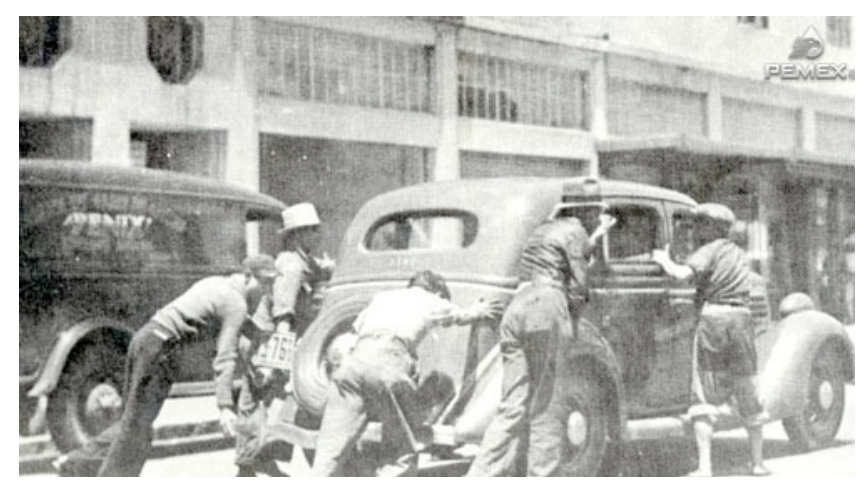

\footnotetext{
¿Se acabó la gasolina? En mayo de 1937, la huelga general de los trabajadores de las plataformas petroleras duró sólo 12 dias; suficiente para paralizar la industria del petróleo y a la nación. La disputa detrás de esta huelga fue causa directa de la expropiación de 1938.
}

En el periodo que corre de ig 52 hasta la década de los setenta, Pemex vivió su "época de oro". En ig66 se creó el Instituto Mexicano del Petróleo (IMP) para promover la autonomía tecnológica. Una gran cantidad de patentes y nuevas tecnologías se produjeron rápidamente, tal es el caso de los grandes descubrimientos de yacimientos petrolíferos en la Sonda de Campeche en ${ }_{197} 8$, resultado de las sinergias entre el IMP y Pemex. Este evento catapultó a México a las grandes ligas como un importante exportador de petróleo. ${ }^{\check{2}}$ ¡Sólo cua- 
tro años antes, México había superado su año récord de producción, el cual había tenido lugar en ig2r! Para ${ }_{197} 8$, la producción se había duplicado con respecto al nivel de 1974 , y para 1982 la producción se había incrementado $126 \%$ por encima del nivel de ${ }_{197} 8$.

Aturdido por los efectos de la "maldición de los recursos", el presidente José López Portillo, poco antes de la caída de los precios del petróleo en I 982 , declaró que el problema de México era "administrar la abundancia”. Fue entonces que el neoliberalismo se introdujo desde Estados Unidos vía las altísimas tasas de interés impuestas a los mercados financieros por los "monetaristas", quienes fueron influidos por Milton Friedman. Meses después llegó una contracción fuerte en las economías del centro y los precios del petróleo se desplomaron, haciendo imposible el refinanciamiento de la enorme deuda externa mexicana.

En el contexto de una gran agitación política y una prolongada recesión económica, de 1982 a ı988, una insurgencia democrática tuvo lugar en las elecciones presidenciales, con el candidato del Frente Democrático Nacional, Cuauhtémoc Cárdenas, hijo del presidente Lázaro Cárdenas, quien en realidad ganó las elecciones, en gran parte debido al enorme apoyo económico del líder sindical de Pemex. ${ }^{16}$ Haciendo uso de su vasto poder institucionalizado para negar la victoria del Frente Democrático Nacional, el Pri, durante el gobierno del presidente Carlos Salinas, arremetió por primera vez contra el sindicato de Pemex en ig89: su liderazgo nacional fue eliminado, con lo que las excepcionales prestaciones de los trabajadores se redujeron drásticamente, y alrededor de 62,ooo puestos de trabajo fueron suprimidos. Lo que siguió fue la reestructuración de Pemex en 1992, a través de la cual todas las actividades se dividieron en cuatro filiales: 1) producción, 2) refinación, 3) procesamiento de gas, y 4) distribución y comercialización. Esta división debilitaría aún más la capacidad de los sindicatos para influir en la política nacional, pues ahora estaban obligados a negociar independientemente con cada subsidiaria. ${ }^{17}$ El contrato laboral de ig 89 permitió a los contratistas privados participar específicamente en un gran espacio de actividades rentables que hasta ese momento eran exclusivas de Pemex, incluyendo exploración, perforación (tierra y mar), construcción, mantenimiento y distribución. ${ }^{18}$ La privatización de Pemex de facto comenzó en r989, e incluyó la reclasificación de una amplia gama de productos petroquímicos como "secundarios"; esto permitió al sector privado mexicano (y a algunas empresas transnacionales) poseer plantas químicas y producir aproximadamente 70\% de todos los productos petroquímicos. ${ }^{19}$

El presidente Calderón intentó profundizar la ya iniciada privatización de Pemex en 2008, sin embargo, en tal intento encontró una fuerte oposición de las fuerzas progresistas y nacionalistas. El resultado de esta confrontación explica, en parte, la debilidad de las fuerzas de oposición en 2013, así como la extrema lentitud de su tibia resistencia; la cual, sin unidad ni coordinación, permitió que la sinergia PRI-PAN lograra la privatización. Con gran éxito, el PAN utilizó una "política rápida" para legislar una nueva ley laboral en 2012. En este y otros casos la oposición no se dio cuenta de las nuevas tácticas utilizadas por sus oponentes para continuar con el proyecto neoliberal. Cuando este proyecto fracasa en la realineación institucional e ideológica del poder social - como pasó en 2008 -, gana fuerza a través de la redefinición de sus métodos. ${ }^{20}$

\section{El capítulo perdido del tLCaN}

Para decepción del clúster conformado por los gigantes de la industria petrolera con sede en Houston, incluyendo ExxonMobil y Shell, y de las empresas de servicios petroleros transnacionales como Schlumberger, Halliburton y Baker Hughes, los negociadores mexicanos del Tratado de Libre Comercio de América del Norte (TLCAN) estaban dispuestos a dar todo, menos el sector petrolero. El capítulo 6 del TLCAN estuvo dedicado al sector energético, siendo esta la única área donde los negociadores mexicanos esencialmente se negaron a ceder en ningún aspecto y nunca consideraron cualquier forma de inversión extranjera directa para el sector. ${ }^{21}$

Pero ahora, con los cambios de diciembre de 2013, bajo las condiciones del TLCAN, las empresas petroleras de Estados Unidos tendrán acceso y trato preferencial en el sector. La iniciativa original de Estados Unidos para la construcción de un bloque económico y de poder en América del Norte (basado en la mano de obra manufacturera mexicana barata y el abundante suministro de energía) para competir con los bloques de JapónAsia y la Unión Europea, experimentará ahora su impulso más fuerte desde i994. Si bien aún no se conocen las cifras exactas, se sabe que existen abundantes suministros de petróleo en los océanos inexplorados de aguas profundas y en los campos de gas de lutita no explotados de México. Empresas de Estados Unidos 
poseen la tecnología de punta y el capital de inversión necesarios para explotar estas reservas. Las implicaciones geopolíticas quizá sean arrolladoras: según el mexicano subsecretario para América del Norte de la Secretaría de Relaciones Exteriores, el bloque del TLCAN, debido a la privatización energética, se convertirá rápidamente en la fuente de energía más importante del mundo. ${ }^{22}$ La lucha de los extranjeros por el tesoro energético puede ahora reanudarse. Después de una espera de 75 años, los magnates del petróleo de Houston podrán proclamar, una vez más, quizá sonando un poco exagerado, "el petróleo es nuestro".

\section{$-\operatorname{notas} \cdot-$}

'Arnaldo Córdova (ı5 de diciembre 2013), "El desmantelamiento de la Constitución”, La Jornada, p. II; Cuautémoc Cárdenas (I/4 de diciembre 2or3), "Rechazo a la reforma energética", La Jornada, p. 4.

${ }^{2}$ Victor Ballinas y Andrea Becerril (I2 de diciembre de 2013), "Presiones de Eu y Canadá, decisivas en la aprobación de la reforma, denuncia PRD”, La Jornada, p. го.

${ }^{3}$ Adam Williams (January 9, 2014), "Surprise Mexican Energy Reform Winner Is Copper Miner",Bloomberg News, en: http:/ www.bloomberg.com/news/20I4-oI-og/surprise-mexican-energy-reform-winner-is-copper-miner.html.

4Notimex (8 de enero de 20I/), “CFE e IP alistan 63,ooo mdd para gasoductos y termoeléctricas”, El Economista, en: http:/ eleconomista.com.mx/industrias/201//or/o8/cfe-e-ip-alistan63ooo-mdd-gasoductos-termoelectricas.

${ }^{5}$ Patricia Muñoz Ríos (8 de enero de 2014), "Debe el sindicato de Pemex solicitar nueva toma de nota", La Jornada, p. 5.

${ }^{6}$ David Martínez Huerta (I4 de enero de 20I4), "Romero Deschamps accedió al despido de miles de trabajadores de Pemex, y por escrito", TIEMPO REAL, en: http://www.sinembargo. $\mathrm{mx} /$ I/4-OI-20I/4/8 7808 .

TImelda García (24 de diciembre de 2013), "Reforma energética, ¿golpea el poder del sindicato de Pemex?", ADN Político. com, en: http:/www.adnpolitico.com/gobierno/2013/12/24/reforma-energetica-inicia-el-fin-del-sindicato- petrolero; Gregorio Vidal (8 de noviembre de 2013), "Remuneraciones de los trabajadores, distribución del ingreso y capacidad de crecimiento de la economía”, El Universal, Sección de Cartera, B2.

${ }^{8}$ Víctor Cardoso (30 de enero de 2013), "Pemex aportó un billón de pesos al erario", La Jornada, p. 29.

9Dolia Estevez (February I, 2013), "Mexican TV Billionaire Salinas Pliego Wants Pemex To Be Privatized", Forbes, en: http:/
www.forbes.com/sites/doliaestevez/2013/o2/oI/mexican-tv-biIlionaire-salinas-pliego-wants-pemex-to-be-privatized/.

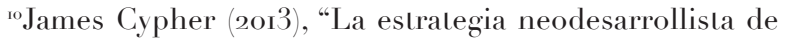
Brasil", Observatorio del desarrollo, vol. 2, núm. 5, pp. I9-23.

"Jason Simpkins (March 7, 2013), "Hugo Chavez is Dead, But His Legacy of Inefficiency Will Live On", Oil \& Energy Daily, en: http://www.oilandenergydaily.com/2013/o3/o7/hugochavez-pdvsa/.

${ }^{12}$ Nora Hamilton (1982), The Limits of State Autonomy, Princeton, Princeton University Press, pp. 2I7, 238.

${ }^{3}$ Ibid., pp. 2I6-2/40.

'4Howard Cline (I962), Mexico Revolution to Evolution: 19401960, New York, Oxford University Press, p. 274.

${ }^{15}$ Secretaría de Energía (Sener), "Historia del IмP", en: http://www.imp.mx/acerca/?imp=hist2, consultado el I/4 de enero de 2014 .

${ }^{16}$ Judith Teichman (1996), Privatization and Political Change in Mexico, Pittsburg, Pittsburg University Press, pp. I73-I 76.

rIbid., pp. 124-126.

${ }^{18}$ Fabio Barboso Cano (I989), "El Nuevo contrato colectivo de Pemex", Momento Económico, 47, p. 28.

"9Daniel Molina (1989), "Pemex: la reprivatización de facto", El Cotidiano, 32, p. 3г.

${ }^{20}$ Jaime Peck (2012), Constructions of Neoliberal Reason, Oxford, Oxford University Press, pp. I6-24.

${ }^{2}$ Maxwell Cameron and Thomas Brian (2002), The Making of NAFTA, Ithaca, Cornell University Press, pp. 36-37.

${ }^{22}$ Roxana González García (ı de enero de 20I4), "Norteamérica será potencia energética: Alcocer", El Financiero, en: http:// www.elfinanciero.com.mx/secciones/economia/49655-norteamerica-sera-potencia-energetica-alcocer.html. 